\title{
THE EURHYTHMICS OF SWANGE DANCE OF THE TIV PEOPLE OF CENTRAL NIGERIA
}

\author{
Omotolani Ebenezer EKPO ${ }^{1 *}$ \\ *1 Federal University Wukari, Taraba State, Nigeria, omotolaeben@gmail.com
}

*Corresponding Author: -

Email: omotolaeben@gmail.com

\begin{abstract}
: -
Eurhythmics in Dalcroze study is defined as the engagement of human body in rhythmic movement and active listening. Jaques-Dalcroze's involvement of Eurhythmics in music pedagogy is aimed at securing steady position for the body and mind as well as a calculated and unconstrained expression of rhythm. African indigenous music and dance is predominantly functional with intensive assignation of the body and soul of the participants to satisfy the rhythmic drum patterns provided by the musicians. The teaching of music in traditional African settings may be generally informal, yet deliberate. The training technique of the notable indigenous dances in Nigeria informally employ the Dalcroze Eurhythmics teaching technique in the step by step movement pattern and dynamics employed during their group practices, especially with younger members of the group. Among the various traditional dance found in the Tiv clan of central Nigeria, the Swange dance is purposefully selected for this study to validate the relevance of Dalcroze to indigenous Nigerian culture, with regard to music and movement. This paper employ the ethnographic study approach; it combines participatory and observation research ethodologyies, theoretical engagement, and ample illustrative style of writing, to portray the everyday complexities of music/dance learning among the people.
\end{abstract}

Keywords: Eurhythmics, Swange dance, Tiv, Dalcroze, Indigenous music, Nigeria

\section{(c) $(\$)$}




\section{INTRODUCTION}

The Tiv is an ethnolinguistic group found in Nigeria and Cameroon. Predominantly situated in the central northern region of Nigeria. The Tiv possess a deep passion for music and dance, possibly more than their cultural neighbours within the region. The Swange dance is one of the prominent indigenous dances of the people. It is a popular Tiv music and dance in Nigeria which started as a folk dance and afterwards went through several repositioning in response to the purview of Tiv socio-economic and political changes. The origin of Swange dance is described as being obscure as a result of its changing and transitional nature, Tijime, (2019). Swange music and dance historically gained popularity in the mid-20th century as a revolutionary dance band that was created by the exigencies of urban life (Gbenika,1993). Swange dance transcends the Tiv immediate social milieu to become a national dance. Teghtegh, (2004) noted that Swange dance has proven an effective rallying point for national integration in dance choreographing.

This dance, like many other prominent African indigenous dances, is being thought and learnt informally, within a family setting or as a cultural group within the society. Dance education setting in most cases consists of the teacher, learners, location, props and so on. This usually engages the corresponding teaching and learning methods and approaches via observation, participation and repetition. The difference between formal and informal dance education is revealed in the limited human cognition, cultural values and philosophies, as well as the instructional techniques engaged in the process. However, there is always a meeting point, and this may be the step by step approach to the teaching and learning itself.

Tijime (2019) opined that human being possesses a unique capacity to learn from others, which doubtlessly informs the ability to dissect complex cultural knowledge and its possible transmission through many generations. Warburton, (2002) on the other hand concluded that pedagogy is a discipline that concerns the study of how best to teach. Besides its formal procedures, its primary focus is on the art and science of instructions inherent in specific human cognition, cultures, histories and technologies. He further viewed the art of dance as the engagement of movement in communicating meaning, even though most dance educators challenge the need for some kind of advancing the appraisal of learning. Dance creation and presentation are widespread activities with a variety of creative and pedagogic milieus that rally around the rehearsal process itself. Rehearsing then simply implies teaching and learning activities. A process traditionally practised among African indigenous societies of which the Tiv is numbered.

Juntunen, (2019) in her argument for Dalcroze Eurhythmics as a pedagogic approach, agreed with Sally Stone's (1985) submission of the flexibility of the Dalcroze teaching approach, with reference to Jaques-Dalcroze's personal ideas of pedagogical principles, such as the belief that students should not be taught rules before they have an experience of them, (Jaques-Dalcroze, 1920/1965, pp. 59-60). She further affirms Juntunen \& Westerlund, (2001) description of Dalcroze learning to be the kind that takes place in interactional processes and through subjective and transformative experiences, with an unpredictable learning outcome. Dalcroze teaching is learner centred with a keen consideration of the personal and cultural differences of students laced on some kind of philosophies or theories that can guide and provide a frame of mind for planning and decision making in the classroom.

Although the cultural pedagogy of Swange dance does not necessarily take place in a formal classroom, except for its practice within the indigenous church settings like the NKST and the Catholic church, where the traditional dances were incorporated into the children Sunday school curriculum - like the MIM (Makeranta Iyange Menmen); it engages the interactive process which naturally fits into the student's personal cultural background. This study with reference to existing literature and field data, draw a conclusion on the relevance of Dalcroze teaching and learning approach to indigenous Nigerian culture, with regard to music and movement.

\section{Methodology}

This study is carried out as qualitative research, using the ethnomusicological approach for data collection and analysis. Through the oral interview, observation and participatory research methodologies, ample data were extracted from the indigenous teachers, students, as well as the members of the selected communities- Jovkyundan, Joota, Kyado and ZakiBiam. Literature on Dalcroze study and indigenous Tiv Swange dance were consulted for theoretical engagement for the study. A simple comparative analysis of the indigenous approach to teaching and learning of the Tiv traditional Swange dance with the Dalcroze Eurhythmics approach to learning was carried out to establish the link between both. Through the illustrative style of writing, the study portrays the everyday complexities of music/dance learning among the Tiv people.

\section{The functionality of Swange dance}

African music and dance are keenly knitted with the multiplicity of Africa cultural identities. In Hanna, (2019), African dance is described as being highly functional, far beyond movements. It is purposeful; uses intentional rhythm; has cultural influences; uses nonverbal body movement in time, space and effort; communicates through locomotion, gesture, posture, stillness, the senses, music and costume; and has standards for each genre. In the same vein, the functionality of Africa dance cut across the human physiological and emotional domain to his spirituality. Akunna (2007:18), affirms the African engagement of dance in their daily activities, either to express joy or grief; love or hate; or evoke prosperity and avert calamity and so on. Adegbite, (2010) linked the cathartic and therapeutic function of dance to peoples' (i.e both the performer and spectator) wellbeing, behaviour and identity when discussing the role of dance in Orósùn festival of SouthWestern Nigeria.

Swange dance among the Tiv and in Nigeria as a whole enhances the socio-cultural interactions and integration of the people and their neighbours; it facilitates the political revolutionary and repositioning movements; it aids socioeconomic restructuring, and serve as a viable tool for therapeutic and religious engagement. The therapeutic function of Swange 
dance helps in boosting mental and physical health, as well as promoting social and emotional cognition. Its flexibility is discovered to help decrease muscular tension.

On the other hand, the socio-cultural interactions and integration of the Tiv people within themselves and their neighbours is largely laced on the language, dressing and occupational engagement of the people. For instance in Sani, (2012), the fluidity body movement of the Swange dancers is believed to be inspired by the flow of the river, and considered mimetic, abstract and metaphorical in varying degrees characteristically. Also, the prominent circular movement of the dancers depicts cultural continuity. In terms of its influence on the Tiv socio-economic restructuring, Swange dance as an arm of the cultural heritage of the Tiv nation, as well as an aspect of a versatile economic sector (music, dance and tourism), doubtlessly improves the economic impact of the state through direct and indirect trade system. In Borg and Russo, (2005), culture-oriented economic development is considered a viable internal means of revenue generation for cities.

\section{The pedagogy of Indigenous Tiv Swange Dance}

"Indigenous dance is an art form that transforms images, ideas, thoughts and feelings into movement sequence that are personally and socially significant" Akas, (2013). All indigenous African communities engage in dance in displaying their cultural musical heritage. It is an art that enjoy remarkable sustainability all through many generations. Virtually all indigenous cultural activities engage music in one way or the other to emphasize its impact on the indigenous people for many decades. The continuity of such socio-cultural practices is being thought of either consciously or unconsciously. Moumouni, (1968), observed that education in Africa must be noted, and cannot be detached from life itself. Traditional education according to Andrew and Anyam, (2011) is described as a functional education that integrates an individual within his/her society for self-reliance.

The Tiv are of the semi Bantu linguistic affinity according to Andrew and Anyam, (2011). They predominantly occupy the Northern and Southern parts of the middle course of the Benue River and its tributary the River Katsina-Ala. The Tiv share boundaries with Anambra and Cross River states on the south and with Taraba and Nasarawa in the North; in the West by Otukpo, Apa and Oju local government areas of Benue state and in the East by the Republic of Cameroon.

"Participatory learning approach has been used traditionally with rural communities in the developing world. There it has been found extremely effective in tapping into the unique perspectives of the rural poor, helping to unlock their ideas not only on the nature and cause of the issues that affect them, but also on realistic solutions" Thomas, (2010).

The indigenous Swange dance of the Tiv people is considered the most decent, popular and loved music style of the Tiv which has survived all kinds of oppositions till now. Historically, the Swange dance is an evolution and fusion of various genres of traditional music in stages from Kwagh-alom or Kikya songs to the more choreographed Ibyamegh and Angye songs and dance to a much more refined and dynamic stage of Swange dance we have today, Tsevende et al (2013). Swange dance is classified into different major groups and subgroups which are being thought and leant for cultural engagement and recreational purposes. Thus, adequate knowledge of the dance and all it entails is essential for outstanding performance at any time.

Knowledge in the words of Lemke, (1994) is a complex body of several socially constructed ideas, validated by the dominant intellectual persuasion at each point in time. Indigenous knowledge then is based on communal understanding and is embedded and conditioned by the culture of the locality in question. The development of indigenous knowledge is a byproduct of efforts to master the environment and has been a matter of survival to the communities. Ezeanya-Esiobu, (2019). In the African indigenous settings, education or acquisition of knowledge is termed life itself, (Moumouni 1968, 18). There is minimal emphasis on abstract learning or formalism as distinct from the day-to-day situations that individuals encounter. Informally, the basic foundation of societal values, knowledge and culture are transmitted to the child through his/her participation in both solid and purposive complex relationships with the members of his/her community. The education of the African child was essentially pragmatic, "virtue was inculcated more through exercise than through precept" (Abraham 1969, 70)

The pedagogy of Indigenous Swange dance is approached as a kind of semi-formal and informal style of learning. Basic rules of the dance are thought as the foundation for the actual stage performance of the dance, this includes the positioning of the body- twisting of the upper and lower limbs, waist and neck and so on. Stage movement from one spot to the other, as well as corresponding gestures to a particular sound, rhythm or word. Also, the dynamics of stage interaction are thought by older members of the group standing in as instructors or teachers. Swange dance is usually presented as a choreographed dance movement, therefore, new members are thought the art of concentration and focus, according to Blessing Nguhmen and Aondona Vanger in an oral interview, during training/rehearsals at MIM, steps, movement and transition are numbered. Even though the art appreciates individual skills and the ability to improvise, more attention is put in place to encourage members' articulation and submission to organized group movement.

More than often, during rehearsals, young and new members are encouraged to move around the practice arena (usually open field) making different gestures with their hands, arms, heads, or upper bodies in response to the rhythms and melodies of the music played. According to Nguhmen and Vanger," sometimes, as small children, we were told to just sit down and watch the experts perform, this helps us understand the way our bodies move in response to the sounds produced on the musical instruments and the songs we sing". Other elements of Swange dance pedagogy include discipline, character, respect, continuity, self-confidence, responsibility, accountability and creativity. 


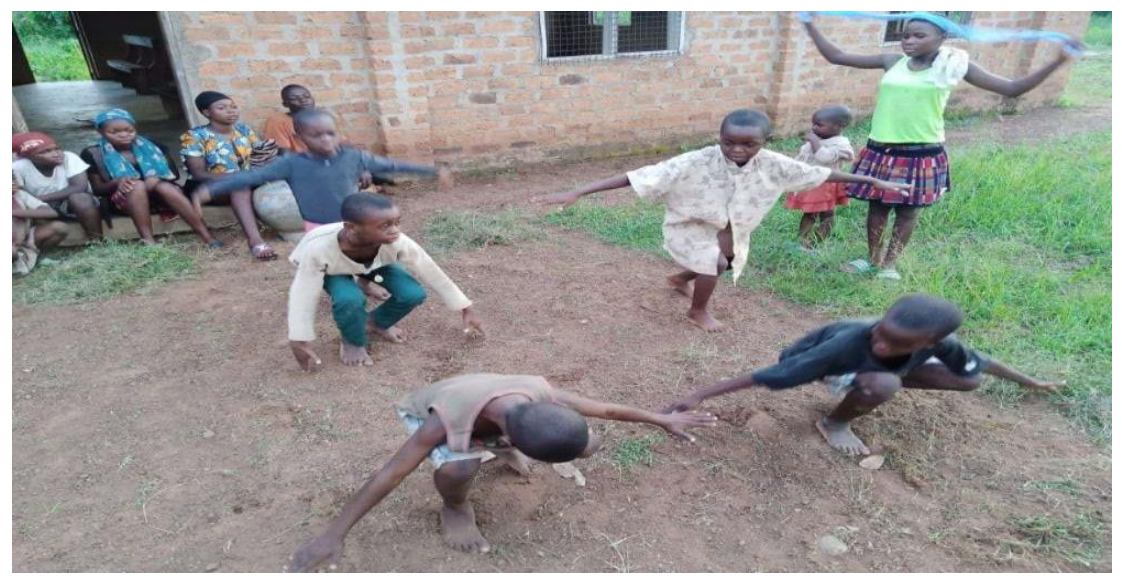

Children of MIM in Jovkyundan Village during rehearsals (source: field work 2021)

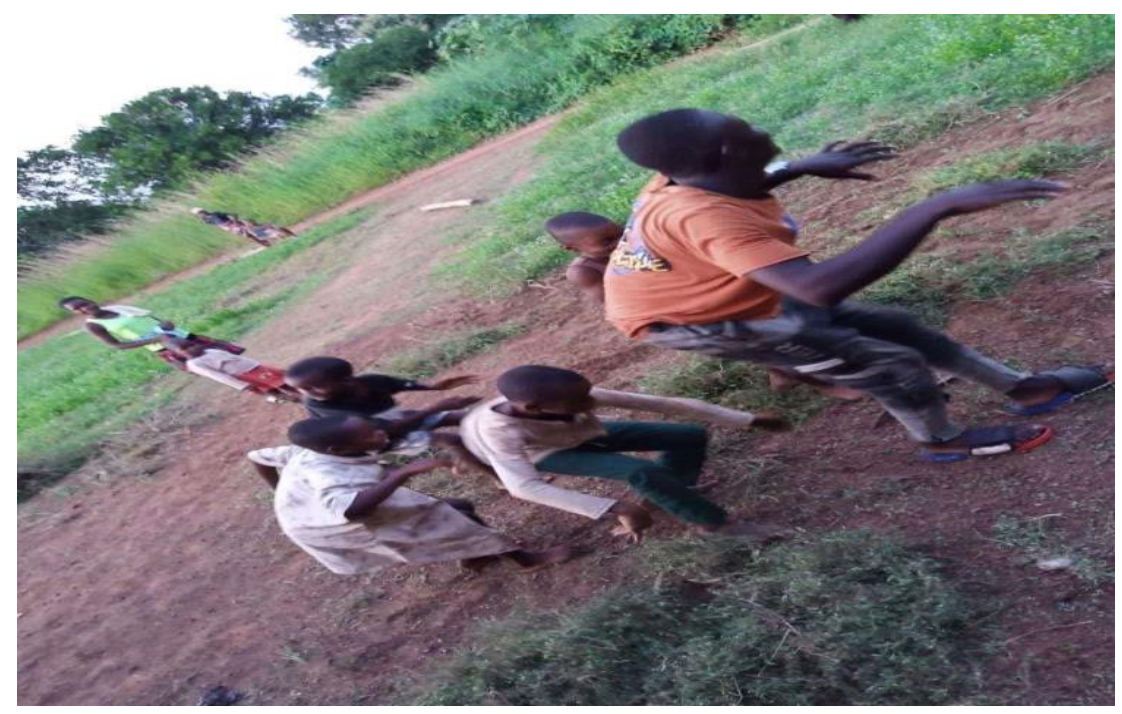

g

Children of MIM in Jovkyundan Village during rehearsals with tutor (source:field work 2021)

\section{An overview of Dalcroze Education Approach (DEA)}

Literature on Dalcroze Education concurrently describes it as a playful, experiential approach to teaching and learning music. It features interactive games and exercises that help students learn to trust their ideas and develop their own intuitions. It is further described as an intuitive style of teaching and learning that cuts across every stage of life with so much ease and enthusiasm for an in-depth musical understanding and improved body awareness. (Dalcroze Society of America, 2021).

For example, a Dalcroze Eurhythmics class may feature free movements by students, who move around making different gestures with their hands, arms, heads, or upper bodies based on certain guidelines in response to the music in the room. (Dalcroze Society of America, 2021). Some of the benefits of the Dalcroze teaching and learning approach were highlighted as enhancing participant's ability to internalize rhythm through the body; comprehension of phrase and form; understanding of different beat types and their corresponding meters; development of the inner ear, as well as the encouragement of aesthetic development in musical performance. Students of Dalcroze also learn to improve on nonverbal expression, breathe control and sense of coordination and balance Dittus, (2020).

\section{Reconciling the Dalcroze approach with the indigenous Swange teaching and learning approach}

The informative power of some traditional dances in connection with participatory learning support is effective in achieving balanced knowledge, skills and attitudes among indigenous people. Some of these indigenous dances over the years have positioned themselves as indispensable tools in aggrandizing community sensitization, education and reformation as submitted by Akas, (2013). Mabingo (2015:132), similarly refers to sequences and protocols of learning such as cross-generational, collective and participatory teaching and learning, which are founded on communal-based performances and consistently responsible for the transference of dance knowledge, skills, and competencies from one individual or group of individuals to another.

The indigenous Tiv Swange dance doubtlessly has successfully positioned itself nationally as an indispensable tool in aggrandizing community sensitization, education and reformation. Its teaching and learning approach encourages individual creative expression. New members of the group start their learning process by observing and admiring the creative body movements and dance display of the outstanding dancers, as means of internalizing the procedures and dynamics of the dance. This may take time as the case may demand. After which they are encouraged to try what they 
saw and interpret the same in response to the music played. Another aspect of the learning may adopt the numbering of steps and movement for easier understanding of the music itself.

However, summarizing Dalcroze's approach to music education, Anderson, (2011) emphasized the importance of Eurhythmics as an element of Dalcroze's approach to music education. It is an approach that simplifies the understanding of rhythm by aligning both the body and mind, as well as deliberate and spontaneous movements in the expression of rhythm. This includes the engagement of the "Follow", "Quick-response activities" and "Canon" techniques in simplifying the learning process of tempo, rhythm and dynamics. Simpler said it is useful in facilitating students understanding of music and group musical ideas within a phrase in musically sound ways with minimal music instructions. To evaluate the relationship between the Dalcroze approach and the indigenous Swange teaching and learning approach, the following elements are considered.

\section{a. Flexible approach to teaching}

Dalcroze approach to teaching music and dance is of the opinion that students should not be taught rules before they have an experience of them. Similarly, the teaching of indigenous Tiv Swange dance recognizes the reality of cultural renewal with each generation as time evolves. Therefore, its teaching reflects thinking back to the learner as a direct flow of expectation, through exchange and context, to the application of experience and vision. From the cultural perspective of Swange training, the purpose of the teaching procedure and thinking is to encourage an individual's personal power through focused attention, repetition, and context.

\section{b. Subjective, interactive and transformative learning process}

Dalcroze employs the interactional processes of pedagogy through subjective and transformative experiences. The indigenous training of the Swange dance honors the reality of subjectivity and interaction, which is always grounded in the natural basics of life. Its teaching and learning process adheres to the most subtle, yet deeply rooted, universals and principles of the people. As a vehicle of utility and expression, it connects the indigenous Tiv people to their inner sources of life, while recognizing the various levels of human maturity.

\section{c. Unpredictable learning outcome}

One of the underlying factors that informs the teaching of the indigenous Tiv Swange dance is the tutor's recognition of the learning requirement of member's creativity and identity. That is, individual dancer's ability to participate effectively and honor relationships with other members of the group, and the community at large, without a rigid guideline for learners. Young members are allowed flexibility in the way they learn. Even though there are basic steps peculiar to the Swange dance, there are dynamics in its presentation with a vivid engagement of their bodies in rhythmic movement and active listening to the music being played. The Dalcroze approach too does not encourage a rigid procedure of learning, rather a conducive learning environment is created for students to express their individuality and cultural identity. By so doing the outcome of the class session cannot be predetermined by the teacher.

\section{d. Leaner center}

Learners/student are central to any teaching activity, there will be no teacher/tutor without an interested person to teach. The Dalcroze pedagogy is centered with keen consideration of the personal and cultural differences of students laced on some kind of philosophies or theories that can guide and provide a frame of mind for planning and decision making in the classroom. Younger group of the Tiv community are considered the carriers of cultural art, values and philosophy to the unborn generation. Therefore they are considered highly important when considering the posterity of a cultural heritage. In the teaching of indigenous Tiv Swange dance the learners are carefully handled and encouraged to pay keen attention to core principles and dynamics as well as traditional philosophies that inform the dance, while they are allowed to improvise on the basics of the dance.

\section{e. Group rehearsals and practice}

Every aspect of learning is step by step, stage by stage and level by level. No virtuoso player, singer or dancer is made in a day. Everyone undergoes training process and consistent rehearsal and practice rigors to attain a post of recognition. The Dalcroze Eurhythmics teaching technique is displayed in the step by step movement pattern and dynamics employed during their group practices and classroom sessions. So also does indigenous learning process recognizes that essential fact that learning can only be complete only if it starts from the beginning and follows through required process. One new skill must build on an existing other, without compromising the importance of the basics.

Considering the Swange dance training approach, actual learning process is realized during group rehearsals and practice, as the learners/students may be left to themselves with minimal supervision and strict instructions. At such rehearsal periods, the children are allowed to move around freely on the field, displaying various gestures with their bodies to derive a new movement that may be recognized and adopted by the group for future performance.

\section{Elements of Eurhythmics from Dalcroze and Swange perspective}

Eurhythmics in Dalcroze study is holistically concerned with the engagement of the human body in rhythmic movement and active listening, with a singular goal of establishing a steady position for the body and mind as well as a calculated and unconstrained expression of rhythm. Without much difference, the daily complexities of music and dance learning among the Tiv people mirrors the predominant position of the functionality of these cultural arts with an intensive 
assignation of the body and soul of the participants, audience and the society at large. For this study, some of the prominent elements of this approach to learning will be briefly discussed.

i. Body positioning: The positioning of the body is integral to the pedagogy of dance. In both formal and informal settings of teaching and learning dance and other forms of art are associated with it. Dancers are taught basic ways of aligning their bodies in an appropriate way that prevents injuries and represent the feelings of the dancer, as well as the message the dance intends to communicate to the audience. Poor body positioning, apart from the adverse health implication, slows down the learning process. Whereas Dalcroze teaching approach presents well-documented eurythmic postures, the Swange dance only have established body postures that are thought from one generation to the other through observation and participation (as oral tradition). However, both approaches of teaching dance, emphasize the importance of self-awareness of the human (dancer's) body; breath control; appropriate functional motion; agility and adequate strength for graceful movement. Students/learners are thought about the flexibility of their body and its ability to listen and interpret sound and rhythm.

\section{ii. Calculated and unconstrained expression of rhythm:}

Motor control in rhythmic dance is keenly concerned with some calculated movements. Both Dalcroze eurhythmics and Swange dance training recognize the fact that dance movements are derived from the synchronization of rhythmic movement of a piece of music with selected body parts of the dancer. Unconstrained expression of rhythmic movement by dancers is usually encouraged during group practice and rehearsals.

iii. Observation and participation approach: Both Dalcroze eurhythmics and Swange dance have common educational aims and objectives of creative performance. The approach of observation and performance is central to the dissemination of basic rules of dance movements. The unending variety of African dance movements provide younger generations a unique and generally acceptable mode of physical exercise for growth and agility, so do Dalcroze Eurhythmics. The dance and the music also serve as cultural vehicles, which encourage team-work.

Although, Dalcroze has a well drafted and documented outline and curriculum for its teaching for many decades, Swange dance has survived many generations basically through oral tradition and lean solely on the strength of observation and performance up till now.

iv. Repetition: Eurhythmics is one of the key aspects of the Dalcroze approach to music pedagogy that enhances the development of certain music creative proficiency and skills. The Dalcroze goal of building students' capacity in listening and music appreciation through the coordination of bodies and minds entails the repetition of certain gestures and body movements over a period of time.

Similarly, the Swange dance of the Tiv through repetition of various body gestures and movements engage the younger minds' creative instincts with respect to pitch and rhythm. More often than not, the trainee follows the instructors' or teacher's movements repeatedly and vice vasa as the case may be. Both approach teaching approaches focus on educating students to gain emotional balance as well as self-expression and regulation.

v. Improvisation: Both African and non-African creative musical activities, give room for improvisation on established musical phrase or sentence either as a melody or rhythmic pattern. In consideration of dance, the Tiv Swange dance training and Dalcroze Eurhythmics practice explore the available physical space to express the various elements of music embedded in a particular piece of music.

With a clear picture of the goal of a performance in mind, students or trainees are encouraged by the teacher to express what he or she could deduce from the music being played. By building on some established movements, they are provided ample room for expansion and dynamic expression within the scope of the theme.

vi. Therapy: Therapeutically, Habron, (2016) described the connectivity of human consciousness and other forms of awareness as an adaptive and transformational tool. Dalcroze Eurhythmic in Harvey's words is considered as being beyond a mere refinement of dancing or an improved method of music education, but rather functions as a principle that must have effect upon every part of life of which wellness is paramount (Harvey et al. 1912: 5 and Habron, 2016).

Similar to this therapeutic scope of Dalcroze practrice, the Tiv indigenous Swange dance involves the holistic role of improving the dancer's health, cognition and social growth through music and movement. The curative and functional properties of Swange dance is evident in its step by step body movements by stretching and twisting of the body. This enables the dancers to maintain a good joint mobility and flexible muscles that protects injuries as a result of muscle stiffness. Swange dance is characterized by consistent stretching of the body which is also helpful in managing stress and relief from anxiety especially when combined with deep rhythmic breathing exercises.

\section{Conclusion}

This study conducted a comparative analysis of the informal indigenous pedagogy of the Tiv Swange dance with the formal Dalcroze study approach on the basis of Eurhythmics. It discussed the similarities of the two learning approaches in the engagement of Eurhythmics as an act of engaging the human body in rhythmic movement and active listening. Both the primary and secondary data collated for the purpose of this study revealed that the Swange dance training like 
the Dalcroze study, is aimed at securing steady position for the body and mind as well as a calculated and unconstrained expression of rhythm. Although, the Tiv indigenous Swange dance is predominantly functional and deliberate in its teaching. The step by step movement pattern and dynamics employed during their group practices, especially with younger members of the group reflects a somewhat unconscious adaptation of the Dalcroze Eurhythmics teaching technique informally. Some inherent elements of both training practices and functions such as: Body positioning, calculated and unconstrained expression of rhythm, observation and participation approach, repetition, improvisation and therapy were highlighted and discussed to validate the study.

\section{Reference}

[1].Abraham W (1969) The mind of Africa University of Chicago, Chicago Akas, N. C. (2013). Indigenous dance as a medium for participatory learning: A study of 'A dance into Manhood' as a paradigm. MGBAKOIGBA: Journal of African Studies. Vol. 2.(pp 18-23).

[2].Andrew, P. A. and Anyam, E. A. (2011).The Dilemma of Traditional Education in Africa: The Tiv Experience. World Educators Forum.

[3].Ezeanya-Esiobu, C. ( 2019). Indigenous Knowledge and Education in Africa. Frontiers in African Business Research Series Editor Almas Heshmati, Jönköping International Business School, Jönköping, Sweden

[4].Dittus J. 92020). What Does Dalcroze Eurhythmics Provide to Dancers? In Music is movement, Dalcroze School of the Rockies.

[5].Dalcroze Society of America, (2021). Dalcroze Education.

[6].Edward C. Warburton ().Dance Pedagogy. The Bloomsbury Companion to Dance Studies Gbilekaa, S. (1993), “Tiv Popular Music and Dance: Myth and Reality" in Ahire, T. (ed.) The Tiv in Contemporary Nigeria, Tiv Studies Project Publication, No.1.

[7].Juntunen, M.-L. (2019). Dalcroze Eurhythmics - a method, an approach, a pedagogy, or a philosophy? Le Rythme 2019, 49-59. Available: https://dalcrozeusa.org/wp- content/uploads/2019/07/Le-Rythme-2019- Webversion.pdf

[8].Lemke J (1994) What is postmodernism and why is it saying all these terrible things. J Accel. Learn Teach.

[9].Moumouni A (1968) Education in Africa. Praeger, New York

[10]. Teghtegh, D. (2004) "Dance and National Integration: Focus on Swange Dance" in Angya et al (eds.) Third Faculty of Arts National Seminar of the Benue State University, Makurdi.

[11]. Thomas, S. (2010). An Introduction to Participatory Learning. London: University Press. 2010. Tijime A. J. (2019). Repositioning Nigerian Music and Dance for Cultural Diplomacy: Lessons from Swange Music and Dance in Nigeria Article.

[12]. Tsevende, R. A., Agber, C. T.,Iorngurun, D. S. and Ugbagir, N. N. (2013). Tiv Swange music and dance. Tim Cutting Agber, Midian Press, Nigeria.

[13]. Hanna, J. L. (2019). Identity in African Dance-Myth and Reality. The Nankama African Dance Conference Proceedings, Howard University, in Evoke: A Historical, Theoretical, and Cultural Analysis of Africana Dance and Theatre 1(1):36-45, Ed(s):Abiola, Of osuwa, https://dh.howard.edu/evoke/

[14]. Adegbite, A. (2010). The impact of African traditional dance: Orósùn example. Journal Media and Communication Studies Vol. 2(6) pp. 133-137, http://www.academicjournals.org/jmcs Sani, M. M. (2012). An adaptation of performance using Swange music to create conceptual paintings through dance steps. Nsukka Journal of the Humanities, Vol.20, pp39-56

[15]. Borg, J. V. and Russo, A. P. (2005). The Impacts of culture on the economic development of cities. European Institute for Comparative Urban Research Erasmus University Rotterdam, Eds: J. Van Der Borg, A.P. Russo Assisted By: M. Lavanga G. Mingardo.

[16]. Anderson, W. T. (2011). The Dalcroze Approach to Music Education: Theory and Applications. General Music Today 26(1) 27-33. National Association for Music Education DOI: 10.1177/1048371311428979 http://gmt.sagepub.com 